\title{
Lista de verificación que debe acompañar a todo trabajo remitido a la Revista Anales de la Facultad de Medicina
}

\section{General}

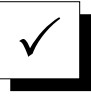

Enviar escaneado de esta página

El artículo se presenta de acuerdo a las instrucciones para los autores de Anales de la Facultad de Medicina.

Se remite por correo electrónico, acompañado por la Declaración Jurada y la Lista de Verificación.

El manuscrito está escrito a doble espacio, con márgenes amplios.

\Se ha numerado las páginas consecutivamente, el apellido del autor está escrito en la esquina derecha de cada página.

Se ha incluido solo abreviaciones estándar.

\section{Primera página}

En la primera página se ha escrito el título, nombre(s) del autor(es), afiliación(es), fuente de financiamiento del estudio y conflicto de intereses.

\Se indica el nombre completo, dirección, teléfono y correo-e del autor a quien se debe enviar la correspondencia.

El título del trabajo no tiene más de 20 palabras y no contiene abreviaturas.

\section{Resumen}

El resumen no excede las 250 palabras. Al final, se ha escrito las palabras clave en número no mayor de cinco. Las palabras clave deben pertenecer al acervo de los Descriptores en Ciencias de la Salud: https://tinyurl.com/y6njpa

Acompaña el Abstract en inglés, con las keywords. Las keywords deben pertenecer al acervo de MeSH NLM: https://meshb.nlm.nih.gov/search

No se coloca notas al pie de la página o referencias en el resumen.

\section{Referencias bibliográficas}

Cumplen con los requisitos de Uniformidad para Manuscritos enviados a Revistas Biomédicas (Estilo de Vancouver).
Las referencias están indicadas en el texto en superíndice, sin paréntesis.

Cada referencia bibliográfica es citada en el texto.

Se enumera las referencias consecutivamente, de acuerdo al orden en que aparecen en el texto.

No se lista en las referencias bibliográficas los datos no publicados ni las comunicaciones personales.

¿as abreviaturas de los títulos de las revistas médicas están en conformidad con las empleadas en el Index Medicus.

No se utiliza punto luego de las iniciales de los autores. Si son más de 6 autores añadir et al. Añadir DOI a las referencias que lo tuvieran.

Tablas

Se presenta cada tabla con su título.

Se enumera las tablas con números arábicos.

Cada tabla contiene la información necesaria, resumiendo y graficando lo explicado en el texto.

Las tablas son cortas y no incluyen información expresada con más detalle en el texto.

No se utiliza líneas verticales.

No se envía más de seis tablas.

Figuras

Cada figura es citada en el texto.

Se envía sonografías, fotomicrografías, radiografías, ilustraciones a color u otras figuras de muy buena calidad, para lograr una buena reproducción.

Las letras y marcas de identificación de las áreas críticas de las radiografías y microfotografías son claras.

Las leyendas y material explicatorio aparecen acompañando a la figura y no escritas en la figura. 